\title{
Recommending Transit: Disentangling users' willingness to recommend transit and their intended continued use
}

\author{
Ehab Diab* \\ e-mail: ehab.diab@utoronto.ca
}

Dea van Lierop**

e-mail: dea.vanlierop@mail.mcgill.ca

\author{
Ahmed El-Geneidy** \\ e-mail: ahmed.elgeneidy@mcgill.ca \\ *Department of Civil Engineering - Transportation Engineering \\ University of Toronto \\ 35 St. George Street \\ Toronto, Ontario, M5S1A4 \\ Canada \\ Tel.: 514-549-0093 \\ Fax: 416-946-8299 \\ **School of Urban Planning \\ McGill University \\ Suite 400, 815 Sherbrooke St. W. \\ Montréal, Québec, H3A 0C2 \\ Canada \\ Tel.: 514-398-4058 \\ Fax: 514-398-8376
}

For citation please use: Diab, E., van Lierop, D. \& El-Geneidy (2017). Recommending Transit: Disentangling users' willingness to recommend transit and their intended continued use for publication. Travel Behaviour and Society, 6, 1-9. 


\section{ABSTRACT}

During the past decade, transit agencies have been trying to increase ridership by attracting new passengers and retaining existing ones. One key strategy to attract new passengers is to encourage current transit users to promote the service to others. However, little is known about the factors that influence riders to become transit promoters. Therefore, this paper attempts to determine the factors that affect passengers' willingness to recommend public transit to a coworker, friend, or family member. In addition, we aim to better understand transit promoters and non-promoters intentions to continue using the service in the future. The study uses a 2014 transit satisfaction survey of users of several bus routes in Montreal, Canada. Descriptive statistics and a logit model are used to understand the factors affecting passengers' willingness to recommend the transit service and their intentions for continued future use. Users' satisfaction with service attributes increase the odds of promoting the service, including satisfaction with their waiting time (3.32 times more), travel time (2.70 times more), and experience on board (1.93 times more). We also found that the intention to continue using transit in the future is not correlated with the willingness to recommend the service to others. The findings of this study can be of interest to marketing and planning departments at transit agencies as it provides new insight into transit passengers' behavior, specifically their willingness to recommend the service to others and their intentions to continue using the service in the future.

KEY WORDS: Bus service, Willingness to recommend, Satisfaction, passengers' intentions, Public transit 


\section{INTRODUCTION}

Public transit systems are essential services needed to ensure the sustainability, equity, and livability of cities. During the past decade, transit agencies have expressed much interest in improving services and many have set goals to increase ridership both by attracting new passengers and retaining existing ones (Diab, Badami, \& El-Geneidy, 2015). Growth in ridership is ultimately important for transport operators, since it raises their revenues and financial efficiency and, in some geographic locations, also helps them apply for federal funding. Levinson and Krizek (2008), among others, illustrated the relationship between improved ridership, funding, and service as a positive feedback loop. For transit agencies, one of the main issues in the quest to maintaining high ridership levels is how new passengers can be attracted to the service. The transport literature tends to discuss the importance of promoting the transit service to non-users through various strategies (Transportation Research Board, 1999, 2003). However, little is known about the factors that influence a users' willingness to recommend the service to others (e.g., to a co-worker, friend, or family member).

In addition to increasing ridership by attracting new users, transit agencies should work on retaining riders for longer periods of time. Individuals stop using transit for many reasons, including changes in income, family size, the availability of another mode, as well as reasons related to the quality of service (Evans, 2004; Grimsrud \& El-Geneidy, 2013, 2014; Perk, Flynn, \& Volinski, 2008). Often, the ideal customer for transit agencies would be someone who is willing to recommend the service to others and who intends to continue using the service in the long term. Accordingly, this research focuses on determining the factors that affect passengers' willingness to recommend the transit service, and sets out to understand whether users who are willing to recommend the service also intend to continue using it in the future. 
This paper begins with a literature review concentrating on factors that influence passengers' intentions of using a transit service and their willingness to recommend it to others and includes studies from the fields of transit and marketing. Next, the data and methods are described. This is followed by an analysis and a discussion of the results of the statistical model. Finally, the paper concludes by outlining the major findings and by discussing relevant policy implications for transit planners and operators.

\section{LITERATURE REVIEW}

\section{Passengers' intentions of using a transit service and quality of service}

One important objective of transit agencies is to increase usage through rider-retention (Murphy, 2014). Accordingly, in order to motivate riders to continue using the service, transit agencies and researchers have begun to recognize the benefit of applying market-oriented research to public transit. One example is an extensive literature review by Molander, Fellesson, Friman, and Skålén (2012), which makes clear that public transit agencies must be market-oriented to meet the increasing competition of other modes. Findings from this study suggest that research on customer satisfaction, experiences, opinions and perceived quality have been useful to understand passengers' needs and positively contribute to improving transit as a public good.

Many studies have focused on the factors influencing public transit users' perceptions and satisfactions with service quality (Diab \& El-Geneidy, 2014; Sadhukhan, Banerjee, \& Maitra, 2014; Susilo \& Cats, 2014; Watkins, Ferris, Borning, Rutherford, \& Layton, 2011). For example, dell'Olio, Ibeas, and Cecín (2011) investigated the quality of service desired by users of a public transport system by assessing the influences of service quality and placed an emphasis on the importance of wait time, travel time, level of occupancy, cleanliness, and 
comfort. In addition, Tyrinopoulos and Antoniou (2008) found that service quality improvements should focus on improving frequency, wait time, and cleanliness. Travel cost is also recognized as being an important aspect of service quality (Chen, 2008; Lai \& Chen, 2011), as well as transit users' overall experience (Carreira, Patrício, Natal, \& Magee, 2014; Friman \& Fellesson, 2009). Several studies also develop methodologies intended to measure satisfaction with service quality over time (de Oña, de Oña, Eboli, \& Mazzulla, 2016) while others investigate which service factors influence passengers to continue using specific transit services (de Oña, de Oña, Eboli, Forciniti, \& Mazzulla, 2016).

In addition to research focusing on quality of service, researchers have also evaluated the relationship between the intention to use transit and actual usage (Chen \& Chao, 2011; Idris, Habib, \& Shalaby, 2014; Spears, Houston, \& Boarnet, 2013). For example, to evaluate a new university bus pass system in Victoria, Canada, Heath and Gifford (2002) used the Theory of Planned Behavior (Ajzen, 1985), to compare students' intentions to use the bus service to their actual usage. These researchers found a strong connection between the intention to use public transit, and actual usage (Heath \& Gifford, 2002). Spears et al. (2013) investigated the impact of attitudes and perceptions on travel behavior in terms of transit use and frequency of use. Nevertheless, there has been little effort to explicitly focus on investigating the relationship between willingness to recommend and intended continued use.

\section{Willingness to recommending the service}

Because the turnover of people using public transit is constant, and transit users tend to be less loyal than users of other modes (Simma \& Axhausen, 2003), it is equally important for transit agencies to retain existing customers as it is to attract new ones (Barlow \& Clark, 2006; Perk et 
al., 2008). This means that transit agencies should not only focus on the needs and desires of exiting users, but also explore ways in which new users can be attracted to the public transport system. While traditional ways of attracting new users include various advertising strategies (Transportation Research Board, 2003), another approach is to assess how new users can become attracted to the service by word of mouth. With this in mind, it has become increasingly important to understand how current transit users can become promoters of the system by being willing to recommend it to a co-worker, friend, or family member.

Previous research has demonstrated that it is important for agencies to understand who is willing to recommend the product or service because companies where many users are willing to recommend also tend to have high growth rates (Reichheld, 2003). For public transit agencies, users who are willing to recommend the service to others are essential, as new users are constantly entering the system and others leaving.

In 2003 Frederick Reichheld published an article in the Harvard Business Review claiming that the question "How likely is it that you would recommend [company X] to a friend or colleague?" is the most important survey question determining continued use of a product. He made this claim after finding that the responses to this question were highly correlated with the responses concerning repeat purchases or referrals in 14 different case studies. Because the results were highly correlated in nearly all cases, he made the claim that the recommendation question could be used as a single indicator to assess a customer's loyalty to a firm (Reichheld, 2003). This measurement tool was intended to provide insight into a company's potential growth, as the customers of companies with high scores are likely to act as advocates who promote the product or service to others through word of mouth. 
However, many researchers do not agree that a customer's loyalty or a company's potential profitability can be measured by a single question survey. For example, even before Reichhled's publication, Hayes (1997) warned against using single questions as he believed they could provide an inaccurate or unreliable evaluation. Today, researchers agree that using multiple, rather than single, question surveys only increase the accuracy of an analysis when all the content of the questions is valid and the question types are appropriate for what is being asked. Therefore, in this paper we attempt to understand which personal characteristics and aspects of an individual's bus trip may influence transit users to be willing to recommend the service. In the transport literature, TCRP Report 47 (Transportation Research Board, 1999) provides a framework for understanding and measuring users' dedication to using transit, with a focus on combining questions including the one related to the willingness to recommend the service to others and intended future use. This framework has previously been used by researchers to understand the impact of improvement strategies on users' perceptions and loyalty (Conlon, Foote, O'Malley, \& Stuart, 2001; Imaz, Nurul Habib, Shalaby, \& Idris, 2015).

Nevertheless, understanding the factors that impacts users' willingness to recommend for others is a topic rarely presented in the public transport literature. In addition, in this paper, we also assess whether the individuals who are willing to recommend the service are also committed to continuing using it themselves. The results of this study provide insight into the relationship between willingness to recommend and the intention of continuing to use the service. 


\section{METHODOLOGY}

\section{Data collection}

The data used in the analysis is derived from a short field survey that was performed along several bus routes in Montreal, Canada, to capture users' perceptions and satisfaction with the service, as well as their willingness to recommend it to others. Six bus routes were considered in the analysis, namely routes 45, 67, 467, 161, 435 and 165. Figure 1 shows the bus routes included in the study. Routes 45, 67, 165, 435 and 467 run north-south serving one metro station at the end of the southern direction, while route 161 runs east-west feeding into one metro station at the end of the western direction. Routes 45, 67, 161 and 165 run for approximately 11.9, 9.5, 11.0 and $7.1 \mathrm{~km}$, offering regular services with an average stop spacing of less than 300 meters, respectively. Routes 467 and 435, overlay with route 67 and 165, and run for 13.0 and $22.4 \mathrm{~km}$, respectively, offering expresses service with an average stop spacing of 600 meters. Routes 45 , 67, 161 and 165 are included as part of a network that is advertised as having a frequency of 10 minutes of less during certain periods of the day. These routes were chosen primarily because they experienced no major changes in their characteristics with regard to route structure and service planning during the study period or in the recent years. They also represent the main and busiest bus routes on the Island of Montreal with the highest numbers of boardings per stop in 2013. In addition, these routes are varied in terms of structure and performance. This selection made it possible to capture both inbound and outbound passengers, as the routes connect residential and commercial areas to major employment centers in the region, such as downtown Montreal. 


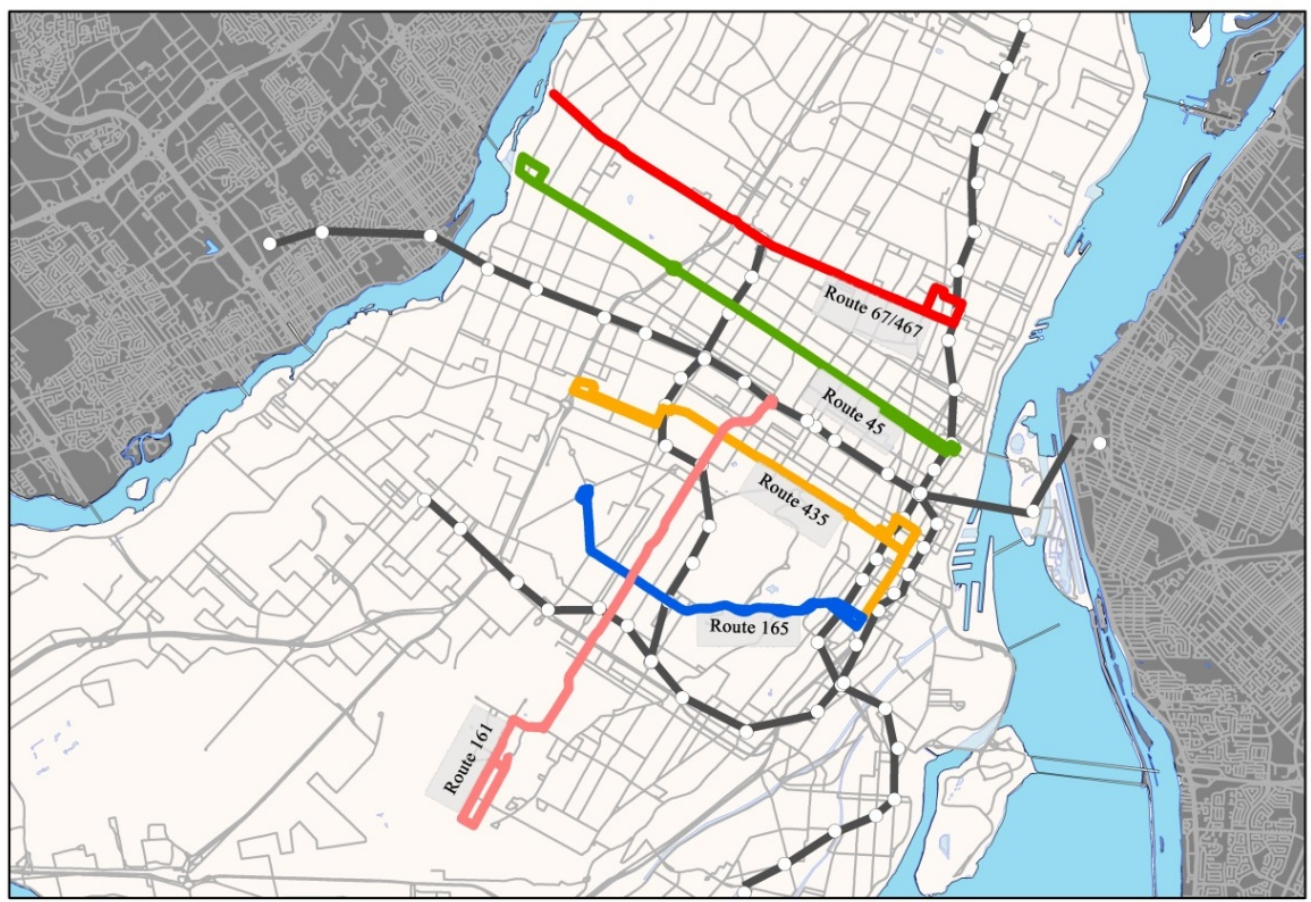

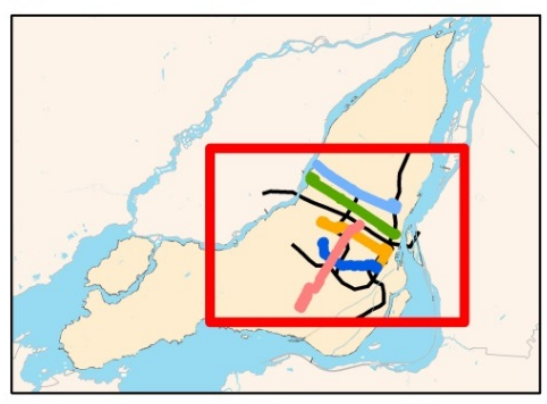

Data Source: STM \& DMTI

\section{Routes}
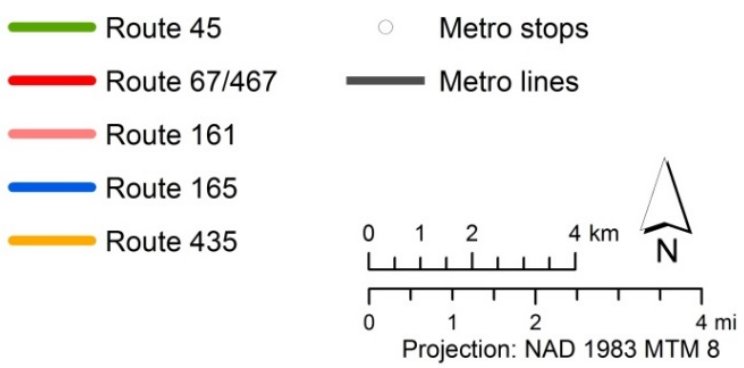

Figure 1: Routes included in the survey

The surveys were carried out from the $15^{\text {th }}$ to the $30^{\text {th }}$ of September 2014 on regular weekdays and weekends between 7:00 am and 10:30 am, and between 2:00 pm and 6:30 pm in order to cover both morning and afternoon commuting periods. The survey was one page long, and included both French and English versions. It should be noted that during the surveying periods, the weather conditions were normal, with no major events impacting the typical bus and metro service. Approximately $90 \%$ of the printed survey sheets were filled out by users, with no observed systematic rejection pattern at any stop. The surveyed passengers were chosen 
randomly, based on who arrived first at the stops. They were provided with writing tools and clipboards to fill out the survey, while the surveyors were standing nearby to provide assistance if needed. Passengers were asked to identify the bus route they were waiting for at a stop, and to indicate when they started using the service. Survey participants were also required to report how frequently they use the route, by selecting one of three options: 1 day a week or less, 2 to 4 days a week, or 5 days a week or more. In addition, they were also asked whether their current trip involved a transfer, either before or after using the bus service in question. Next, the survey required users to indicate their level of satisfaction with their waiting time, travel time, experience on board and cost of trip using rating systems $(1=$ unsatisfied to $5=$ very satisfied $)$. Experience on board was included in the survey to better understand transit users' level of comfort during transit trips, which may have an impact on their willingness to recommend the transit service to others and/or their intend future use.

Participants were also asked to report whether or not they would recommend the bus service to a family member, co-worker or a friend (i.e. Would you recommend the bus service to a family member, co-worker or a friend?). Two options (checkboxes) were given: a) yes and c) no. Additionally, the survey required users to indicate for how many months or years they intended to use the bus service in the future (i.e., How many months or years do you intend to use this bus service?). Expected answers for this question included adding the amount of time or a comment that described their intentions. Finally, the surveys requested the participants to report their age, gender, and home postal code and to add optional comments. A total of 440 surveys were conducted. Nevertheless, similarly to other studies found in the literature where surveys were conducted at bus stops (Diab \& El-Geneidy, 2014; Hess, Brown, \& Shoup, 2004; Mishalani, McCord, \& Wirtz, 2006; Psarros, Kepaptsoglou, \& Karlaftis, 2011), some 
respondents could not answer all the questions because the bus arrived before they finished completing the survey. As a result, several of the surveys were not completed, decreasing the response rate for some of the last questions, including home postal code.

Each surveying team included three members, two individuals to survey passengers, and one to record the arrival times of the passengers and the buses in comparison to bus schedules. This technique was used in order to understand the amount of time that people budget before the bus arrivals and to get a snapshot of their actual waiting time. The observation sheet contained the passenger time stamp, which is the time at which each passenger arrived at the stop, based on the last bus departure. Other information collected on this sheet included the arrival and departure times of each bus, as well as the number of people at a bus stop. Passengers' waiting time was based on the difference between their arrival time at the stop and the time the bus arrived; passengers' waiting time was compared to the bus schedules to determine every passenger's actual budgeted waiting time.

\section{Analysis methods}

In this research, we use descriptive statistics and one binary logistic statistical model based on the survey data to determine the various attributes influencing passengers' willingness to recommend the transit service to others. Table 1 includes a detailed description of the variables incorporated in the statistical analysis. Other variables were tested but were eliminated from the study due to their non-significance, such as age, gender, direction, time of the day and trip transfer. Other variables were not included due to their correlation with other used variables (with a Pearson coefficient of greater than 0.65) such as articulated bus and bus frequency 
variables. The following function shows the model specification of the binary logit model (i.e., Willingness to recommend variable as a dependent variable).

1. Willingness to recommend $=f$ (Waiting time satisfaction, Travel time satisfaction, Experience on board satisfaction, Cost of trip satisfaction, Weekday, Less than 10 minutes, Work purpose, 2 to 4 days a week ,5 days a week or more, Actual waiting time)

The second part of the analysis attempts to better understand the characteristics of users who intend to use the service in the future in relation to their willingness to recommend the service to others. Respondents who indicated that they are willing to use the service forever, for a long time, or for four years or more are grouped together and are considered to be long term users. Passengers who indicated that they will use the service for less than four years, until they get a car, or only as long as they need it were considered as short term users who do not intend to continue using the service in the future. This second phase of the paper uses descriptive statistics as the data is derived from a survey question that accepted a variety of response-types; for example, while some respondents wrote comments such as "for a long time," others simply stated the expected number of years. Therefore, because the question was open-ended it has been analyzed using a descriptive-statistic approach. 


\section{Table 1: Description of variables used in the analysis}

\begin{tabular}{|c|c|}
\hline Variable name & Description \\
\hline Willingness to recommend & $\begin{array}{l}\text { A dummy variable equaling one if the user indicates that he or } \\
\text { she is willing to recommend the service to others and zero } \\
\text { otherwise (dependent variable). }\end{array}$ \\
\hline Waiting time satisfaction & $\begin{array}{l}\text { A dummy variable equaling one if the user indicates that he or } \\
\text { she is satisfied or very satisfied (i.e., } 4 \text { or } 5 \text { out of } 5 \text { ) with his or } \\
\text { her waiting time and zero otherwise. }\end{array}$ \\
\hline Travel time satisfaction & $\begin{array}{l}\text { A dummy variable equaling one if the user indicates that he or } \\
\text { she is satisfied or very satisfied (i.e., } 4 \text { or } 5 \text { out of } 5 \text { ) with his or } \\
\text { her travel time and zero otherwise. }\end{array}$ \\
\hline Experience on board satisfaction & $\begin{array}{l}\text { A dummy variable equaling one if the user indicates that he or } \\
\text { she is satisfied or very satisfied (i.e., } 4 \text { or } 5 \text { out of } 5 \text { ) with his or } \\
\text { her experience on board and zero otherwise. }\end{array}$ \\
\hline Cost of trip satisfaction & $\begin{array}{l}\text { A dummy variable equaling one if the user indicates that he or } \\
\text { she is satisfied or very satisfied (i.e., } 4 \text { or } 5 \text { out of } 5 \text { ) with the } \\
\text { cost of trip and zero otherwise }\end{array}$ \\
\hline Weekday & $\begin{array}{l}\text { A dummy variable equaling one if the survey was collected } \\
\text { during a weekday and zero otherwise }\end{array}$ \\
\hline Less than 10 minutes & $\begin{array}{l}\text { A dummy variable equaling one if the survey was collected } \\
\text { during a period of headway of } 10 \text { minutes or less }\end{array}$ \\
\hline Work purpose & $\begin{array}{l}\text { A dummy variable equaling one if the users' trip purpose was } \\
\text { work and zero otherwise }\end{array}$ \\
\hline 2 to 4 days a week & $\begin{array}{l}\text { A dummy variable equaling one if the user indicated that he or } \\
\text { she uses the service } 2 \text { to } 4 \text { days a week and zero otherwise }\end{array}$ \\
\hline 5 days a week or more & $\begin{array}{l}\text { A dummy variable equaling one if the user indicated that he or } \\
\text { she uses the service } 5 \text { days a week or more and zero otherwise }\end{array}$ \\
\hline Actual waiting time (s) & Users' observed waiting time in seconds \\
\hline Passengers intending to continue & $\begin{array}{l}\text { A dummy variable equaling one if the users indicated that he or } \\
\text { she is willing to use the service for forever, for a long time, or } \\
\text { for four years or more }\end{array}$ \\
\hline Passengers don't know & $\begin{array}{l}\text { A dummy variable equaling one if the users indicated that he or } \\
\text { she does not know to what extent they will use the service in the } \\
\text { future }\end{array}$ \\
\hline Passengers not intending to continue & $\begin{array}{l}\text { A dummy variable equaling one if the users indicated that he or } \\
\text { she is willing to use the service until he or she get a car, as he or } \\
\text { she need, or for less than four years }\end{array}$ \\
\hline
\end{tabular}

\section{APPLICATION}

\section{General description of surveys answers}

Table 2 presents a general summary of the survey respondents. Approximately $85 \%$ of the surveyed sample is willing to recommend the service to the others. Those who are willing to recommend the service are generally satisfied with the service attributes. About $49 \%$ of the users 
who would recommend the service to others are satisfied with their waiting time and $67 \%$ with their travel time, with a standard deviation of 0.50 and 0.47 points, respectively. In contrast, only $14 \%$ of the users who would not recommend the service are satisfied with their waiting time and $28 \%$ with their travel time, respectively, with a standard deviation of 0.35 and 0.27 points. This shows a gap in satisfaction between the two groups (i.e., those who are willing to recommend the service and those who would not), with a $35 \%$ and $40 \%$ gap in the number of people who are satisfied with their waiting and travel time, respectively. The difference in standard deviation between the two groups shows a consistency in answers among the users who do not recommend the service. A similar trend is observed regarding users' satisfaction with their experience on board and the cost of the trip. Users who are willing to recommend the service generally have a 59.4 second shorter waiting time than others. This difference was statistically significant ( $\mathrm{t}(440)$ $=2.8, \mathrm{p}<0.05)$, and shows that these users are able to adjust their arrivals to bus schedules.

Regarding the other personal and service variables, Table 2 shows that $61 \%$ of the users who would recommend the service to others use the service five days a week or more and $23 \%$ use the service two to four days a week. Similarly, $67 \%$ of the users who would not recommend the service to others use it five days a week or more and $16 \%$ use the service two to four days a week. Around $45 \%$ of the users were waiting for a service that has a headway of ten minutes or less. Approximately $40 \%$ of the promoters, and $67 \%$ non-promoters use the service for work purposes. And, around $76 \%$ and $89 \%$ of the promoters and non-promoters, respectively, filled out the survey during weekdays. It seems that promoters' average age is less than the nonpromoters' by four years, however this difference is not significant $(\mathrm{t}(389)=-1.9, \mathrm{p}>0.05)$. Nevertheless, in order to better understand the previous findings while controlling for a set of influential variables, a statistical model is presented in the following section. 
Regarding the users' intentions to continue using the service, only 330 respondents were able to complete this question before the arrival of their bus. Of these, $42 \%$ indicated that they intended to continue using the service in the future (long-term users), $49 \%$ stated that they were not willing to continue to use it, and $9 \%$ reported that they did not know if they would. Table 2 shows that the intention to continue to use transit in the future is not correlated with the willingness to recommend the service to others $\left(\mathrm{X}^{2}=0.26, \mathrm{~N}=300, \mathrm{p}>.05\right)$. In other words, only $41 \%$ of the users who would recommend the service to others intend to continue using it in the future, while interestingly about $47 \%$ of the users, who do not recommend the service, do intend to continue using the service. This relationship is discussed in further detail in the following section of the paper.

Table 2: Summary statistics

\begin{tabular}{|c|c|c|c|c|c|c|}
\hline & \multicolumn{2}{|c|}{ All passengers } & \multicolumn{2}{|c|}{$\begin{array}{c}\text { Recommending } \\
\text { the service }\end{array}$} & \multicolumn{2}{|c|}{$\begin{array}{c}\text { Not recommending } \\
\text { the service }\end{array}$} \\
\hline & Mean & $\begin{array}{c}\text { Std. } \\
\text { Deviation }\end{array}$ & Mean & $\begin{array}{c}\text { Std. } \\
\text { Deviation }\end{array}$ & Mean & $\begin{array}{c}\text { Std. } \\
\text { Deviation } \\
\end{array}$ \\
\hline Willingness to recommend & 0.85 & 0.35 & 1.00 & 0.00 & 0.00 & 0.00 \\
\hline Waiting time satisfaction & 0.44 & 0.50 & 0.49 & 0.50 & 0.14 & 0.35 \\
\hline Travel time satisfaction & 0.61 & 0.49 & 0.67 & 0.47 & 0.27 & 0.45 \\
\hline Experience on board satisfaction & 0.54 & 0.50 & 0.58 & 0.49 & 0.28 & 0.45 \\
\hline Cost of trip satisfaction & 0.46 & 0.50 & 0.49 & 0.50 & 0.25 & 0.44 \\
\hline Weekday & 0.78 & 0.42 & 0.76 & 0.43 & 0.89 & 0.31 \\
\hline Less than 10 minutes & 0.46 & 0.50 & 0.46 & 0.50 & 0.44 & 0.50 \\
\hline Work purpose & 0.44 & 0.50 & 0.40 & 0.49 & 0.67 & 0.47 \\
\hline 2 to 4 days a week & 0.22 & 0.42 & 0.23 & 0.42 & 0.16 & 0.37 \\
\hline 5 days a week or more & 0.62 & 0.49 & 0.61 & 0.49 & 0.67 & 0.47 \\
\hline Actual waiting time & 315.0 & 159.2 & 306.3 & 159.2 & 365.8 & 151.1 \\
\hline Average age & 35.87 & 15.36 & 35.20 & 15.11 & 39.63 & 16.29 \\
\hline Number & \multicolumn{2}{|c|}{440.00} & \multicolumn{2}{|c|}{376.00} & \multicolumn{2}{|c|}{64.00} \\
\hline Passengers intending to continue & 0.42 & 0.49 & 0.41 & 0.49 & 0.47 & 0.50 \\
\hline Passengers don't know & 0.09 & 0.29 & 0.09 & 0.29 & 0.07 & 0.25 \\
\hline Passengers not intending to continue & 0.49 & 0.50 & 0.49 & 0.50 & 0.47 & 0.50 \\
\hline Number & \multicolumn{2}{|c|}{330.00} & \multicolumn{2}{|c|}{285.00} & \multicolumn{2}{|c|}{45.00} \\
\hline
\end{tabular}




\section{Who is willing to recommend the service?}

A binary logistic model was developed to understand the probability of users' to recommend the service to others. Table 3 presents the results of the model which contains 440 observations and explains about $31 \%$ of the variation in users' willingness to recommend the service to others. Regarding the key policy variables, the model indicates that users' satisfaction with service attributes increases the odds of being willing to recommend the service. Users who are satisfied with their waiting time are 3.32 times more likely to recommend the service compared to other users who are not satisfied with their waiting time. Therefore, transit agencies should work on improving users waiting time satisfaction in order to increase their willingness to recommend the service to others. In addition, being satisfied with the trip's travel time and experience on board also have a statistically significant impact on users' willingness to recommend the service to others. Users who are satisfied with travel time are 2.7 times more likely to recommend the service to others compared to those who are unsatisfied with travel time. In addition, those who are satisfied with the experience on board are 1.97 times more likely to recommend the service compared to those who are unsatisfied with the on board experience. Satisfaction with the cost of the trip did not show a significant impact on the odds of recommending the service to others. In other words, the more satisfied a person is with his or her waiting and travel time, the more likely he or she becomes to recommend the service to others. Therefore, transit agencies should implement various improvement strategies in order to keep and increase users' satisfaction with their waiting and travel time, and to a lesser degree, strategies that improve uses' experience onboard.

Users who travel on weekdays are $73 \%$ less likely to promote the service compared to those who travel during weekends. This can be related to the differences between weekday and weekend users, as has been found in previous research conducted in Montreal (van Lierop \& El- 
Geneidy, 2015). Service headway has a statistically significant impact on users' willingness to recommend the service to others. Passengers waiting for a service that has a headway of ten minutes or less are more likely to recommend the service by $74 \%$ compared to users who are waiting for service with more than 10 minutes headway. This finding suggests that improving bus service frequency will have a positive impact on ridership because willingness to recommend increases amongst existing users of frequent services.

Users travelling to work are $61 \%$ less likely to recommend the service compared to all other trip purposes. Frequent users who use the service two to four days a week or five days a week or more are 2.8 times and 2.3 times more likely to recommend the service, respectively, compared to others who use the service once a week. Therefore, attracting more passengers to use the service frequently (more than once a week) is expected to increase their odds of promoting the service, while keeping all other variables at their mean values. Finally, every second increase in users' budgeted waiting time would decrease their odds of recommending the service by $0.1 \%$. Therefore, using several strategies such as bus real time information, which has a positive impact on decreasing users' actual waiting time (Watkins et al., 2011), is likely to have a positive impact on increasing the users' willingness to recommend the service to others. While the results of the model presented in Table 3 have made clear what influences a transit user to more likely to recommend the service to others, it does not assess whether those who are willing to recommend also intend to continue using it in the future themselves. The following section accordingly provides insight into the relationship between willingness to recommend and the intention to continue using the service. 
Table 3: Model for willingness to recommend

\begin{tabular}{|c|c|c|c|c|c|}
\hline \multirow[b]{2}{*}{ Variable } & \multirow[b]{2}{*}{ Coefficient } & \multirow[b]{2}{*}{ Z } & \multirow{2}{*}{$\begin{array}{l}\text { Odds } \\
\text { ratio }\end{array}$} & \multicolumn{2}{|c|}{$95 \%$ Conf. Interval } \\
\hline & & & & $\begin{array}{l}\text { Lower } \\
\text { Bound } \\
\end{array}$ & $\begin{array}{l}\text { Upper } \\
\text { Bound }\end{array}$ \\
\hline Constant & 1.79 & $8.22 * * *$ & 5.99 & & \\
\hline Waiting time satisfaction & 1.20 & $8.62 * * *$ & 3.32 & 1.49 & 7.42 \\
\hline Travel time satisfaction & 0.99 & $8.11 * * *$ & 2.70 & 1.36 & 5.34 \\
\hline Experience on board satisfaction & 0.66 & $3.70 * *$ & 1.93 & 0.99 & 3.77 \\
\hline Cost of trip satisfaction & 0.55 & 2.49 & 1.73 & 0.88 & 3.44 \\
\hline Weekday & -1.31 & $7.17 * * *$ & 0.27 & 0.10 & 0.70 \\
\hline Less than 10 minutes & 0.55 & $2.78 *$ & 1.74 & 0.91 & 3.33 \\
\hline Work purpose & -0.93 & $7.75 * * *$ & 0.39 & 0.20 & 0.76 \\
\hline 2 to 4 days a week & 1.03 & $3.41 *$ & 2.79 & 0.94 & 8.30 \\
\hline 5 days a week or more & 0.84 & $3.39 *$ & 2.32 & 0.95 & 5.66 \\
\hline Actual waiting time & -0.002 & $5.06 * *$ & 0.99 & 1.00 & 1.00 \\
\hline $\mathrm{N}$ & \multicolumn{5}{|c|}{440.00} \\
\hline Nagelkerke R Square & \multicolumn{5}{|c|}{0.31} \\
\hline Log likelihood & \multicolumn{5}{|c|}{280.90} \\
\hline $\begin{array}{l}\text { Bold indicates statistical signific } \\
* * * \text { Significant at } 99 \% * * \text { Signif }\end{array}$ & $95 \% *$ Signi & at $90 \%$ & & & \\
\hline
\end{tabular}

\section{The relationship between willingness to recommend and intended continued use}

As indicated in the summary statistics presented in Table $2,42 \%$ of passengers intend to continue to use the service in the future regardless of their willingness to recommend it to others. Similarly, $49 \%$ of passengers do not intend to continue using the service even though approximately half would recommend it. However, it seems that individual aspects of passengers' transit trips influence their willingness to recommend and intended future use in different ways. For example, Figure 2 demonstrates that the number of users who are satisfied with the service attributes of transit is greater for users who intend to continue to use transit in the future and who are willing to recommend it to others. This is true for satisfaction with travel time, experience on board, and cost, but not the case for waiting time where regardless of users' intention to continue using the service, they are willing to recommend it to others. More specifically, nearly half of the users who intend to continue using the service and would recommend it to others are satisfied with the wait time (49\%) and cost (49\%). These users are 
even more satisfied with travel time $(75 \%)$ and their overall travel experience $(60 \%)$. In terms of statistical significance, Chi-square test of independence was performed to examine the difference in satisfaction among users who intend to continue to use the service and to recommend it and other users. The results suggest that while there are observable differences in Figure 2, satisfaction with transit services does not have a significant impact on passengers' intentions to continue to use the service in the future, except for satisfaction of their travel time. In other words, users who are more satisfied with the service travel time are more likely to continue using the service and recommend it to others $\left(X^{2}=9.8\right.$ to $\left.5.8, N=300, p<0.05\right)$. It should be noted that in this section we focus specifically on the users who indicated their intention to continue using the service or not (around 300 respondents), while people who reported that they did not know if they would continue using the service in the future were removed from the analysis.

Figure 2 also makes clear that users who do not intend to continue using the service, but who would recommend it are also satisfied with the wait time (52\%), travel time (64\%), experience (59\%), and cost (48\%). However, users who would not recommend the service regardless of their intent to continue using the service are not satisfied with the service. This was significant for all the satisfactions variables $\left(\mathrm{X}^{2}=24.8\right.$ to $\left.5.8, \mathrm{~N}=300, \mathrm{p}<0.05\right)$. Therefore, transit agencies should focus on addressing the factors that improve users' satisfactions in order to retain users as well as increase their willingness to recommend the service for others, by focusing on travel time satisfaction. 


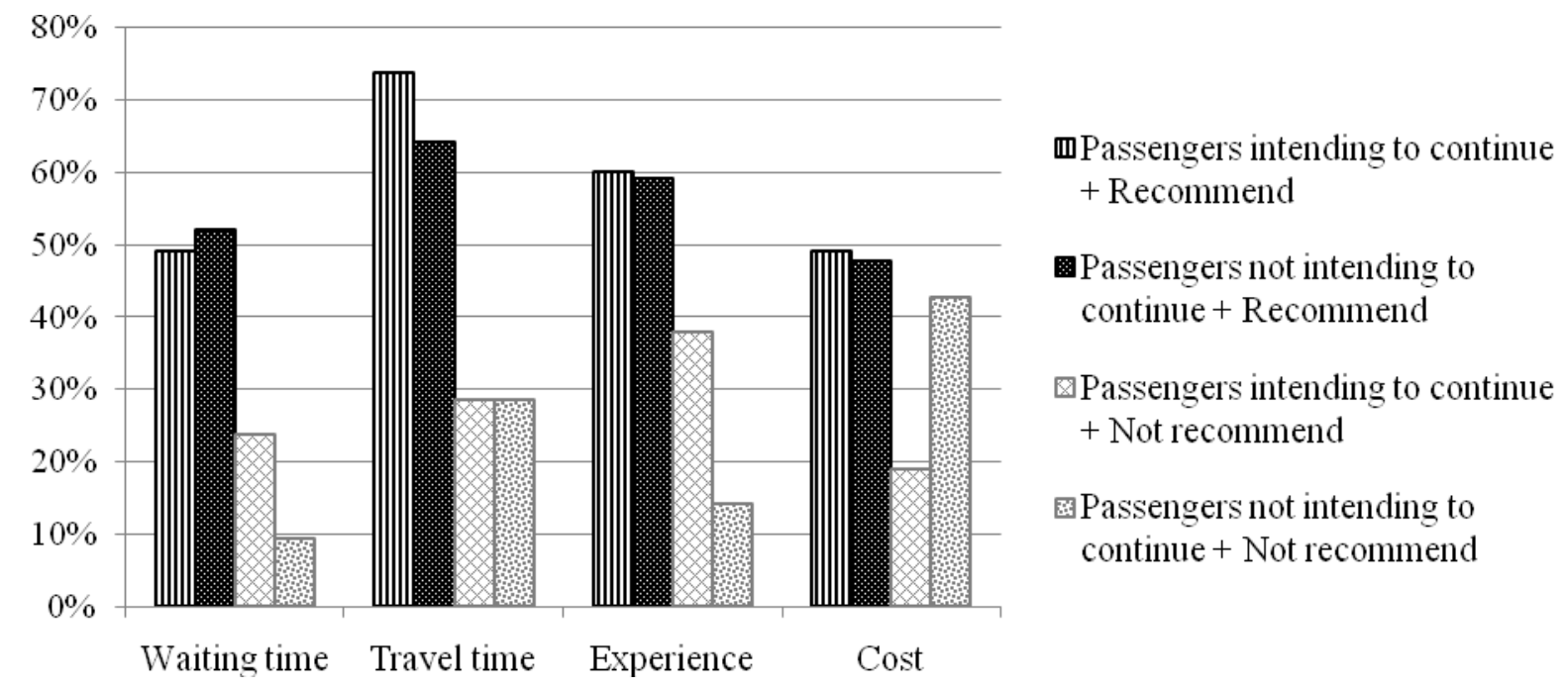

Figure 2 : Percentage of users satisfied with different aspects of their trip

Transit users who would not recommend the service have longer average waiting times than those who would recommend the service (Table 1), regardless of their intentions to use the service in the future. In other words, users who intend to continue to use the service in the future do not enjoy significantly shorter or longer waiting times than others; $t(298)=0.7, p>0.05$. A similar trend can be found for users who intend to continue to use the service in the future and recommend it to others. These findings echo those from the model presented in Table 3, and suggest that increasing bus frequency and using strategies that have an impact on users' actual waiting time, such as bus real time information, will increase users' likeliness to recommend the service to others, but not significantly influence riders to continue using the service in the future. Thus, it seems that the intention to continue using the service in the future is not correlated with the willingness to recommend the service to others, but instead, is likely to be related to other, unexplored factors.

Users who intend to use the service in the future and would recommend it to others are not statistically different from any other group in terms of their weekly usage or frequency of usage. However, with regard to age, we observed that users who intend to continue using the 
service are significantly $(t(281)=-5.9, p<0.05)$ older with an average age of 40 years, compared to those who do not intend to continue to use it, and who have an average age of 30 years. Similar trend can be found for users who intend to continue to use the service in the future and recommend it to others $(t(281)=-3.8, p<0.05)$. This finding suggests that younger users may intend to go through more lifestyle changes that would cause them to change modes such as moving to a farther location that would require the use of a car or increasing their income which would allow them to have more variety in their mode choice. Older users are more likely to have developed a habit, and may have fewer plans to change their lifestyles in the future.

In conclusion, the users who are willing to recommend the service to others are not necessarily the same users who intend to use the transit system in the future. Therefore, the intention to continue to use the service in the future is not correlated with the willingness to recommend the service to others. Generally, users who are willing to recommend the service to others and who intend to continue using it tend to be older, have shorter waiting times and are satisfied with the service characteristics of the trip, particularly their travel time.

\section{POLICY RECOMMENDATIONS}

The results of this study demonstrate that improvements to particular service attributes are expected to increase a user's likeliness to recommend transit to others. Most significantly, the more satisfied a person is with his or her waiting and travel time, the more likely he or she is to recommend the service to others (3.32 more likely). Therefore, transit agencies should implement various improvement strategies in order to keep and increase users' satisfaction with their perceived waiting and travel time. 
One way to make improvements to the way passengers perceive waiting and travel time is to develop more frequent services and implement strategies such as bus real time information. For example, the STM's iBus program which is being rolled out in 2015 and 2016, is expected to have a positive impact on increasing the users' willingness to recommend the service to others. The users who are willing to recommend the service are not necessarily the same ones that intend to use it in the future. In other words, the intention to continue to use the service in the future is not correlated with their willingness to recommend the service to others in many aspects. Generally, users who are willing to recommend to others and who intend to continue using it are older people and who are satisfied with the service characteristics of the trip, particularly their travel time. This means that transit agencies should focus on continuing to improve transit travel times and develop strategies to increase overall perceptions of service quality.

To illustrate how our research fits into the larger framework of transit ridership, Figure 3 shows a conceptual context of the determinants of ridership levels. As seen in the figure, transit ridership is determined by the number of new users who enter the service, and the number of users who decide to stop using it, in addition to those who were using it in the past and plan to continue use it in the future. New users start taking transit because they experience a lifestyle change such as a change in income, residential location, family structure, or the (un)availability of another options (Perk et al., 2008). However, not all new users change their mode to transit because of a lifestyle change; some may be curious to try taking transit because the service attractiveness and due to their social groups (family members, friends, co-workers) recommend the service. These new users would be a result of positive word-of-mouth interactions, and in order for these to occur it is important for transit agencies to understand what makes a rider more likely to recommend the service (the blue arrow in the figure). 
Figure 3 demonstrates that a transit agencies' ridership level is also dependent on the number of people who leave the system. Although many passengers make the switch from using transit to taking another mode due to lifestyle changes, many users also stop using the service because they are unsatisfied and have the opportunity to change to another mode. Therefore, it is in the transit agencies' best interests to understand how to increase the satisfaction of existing users to avoid such loss in ridership as much as possible.

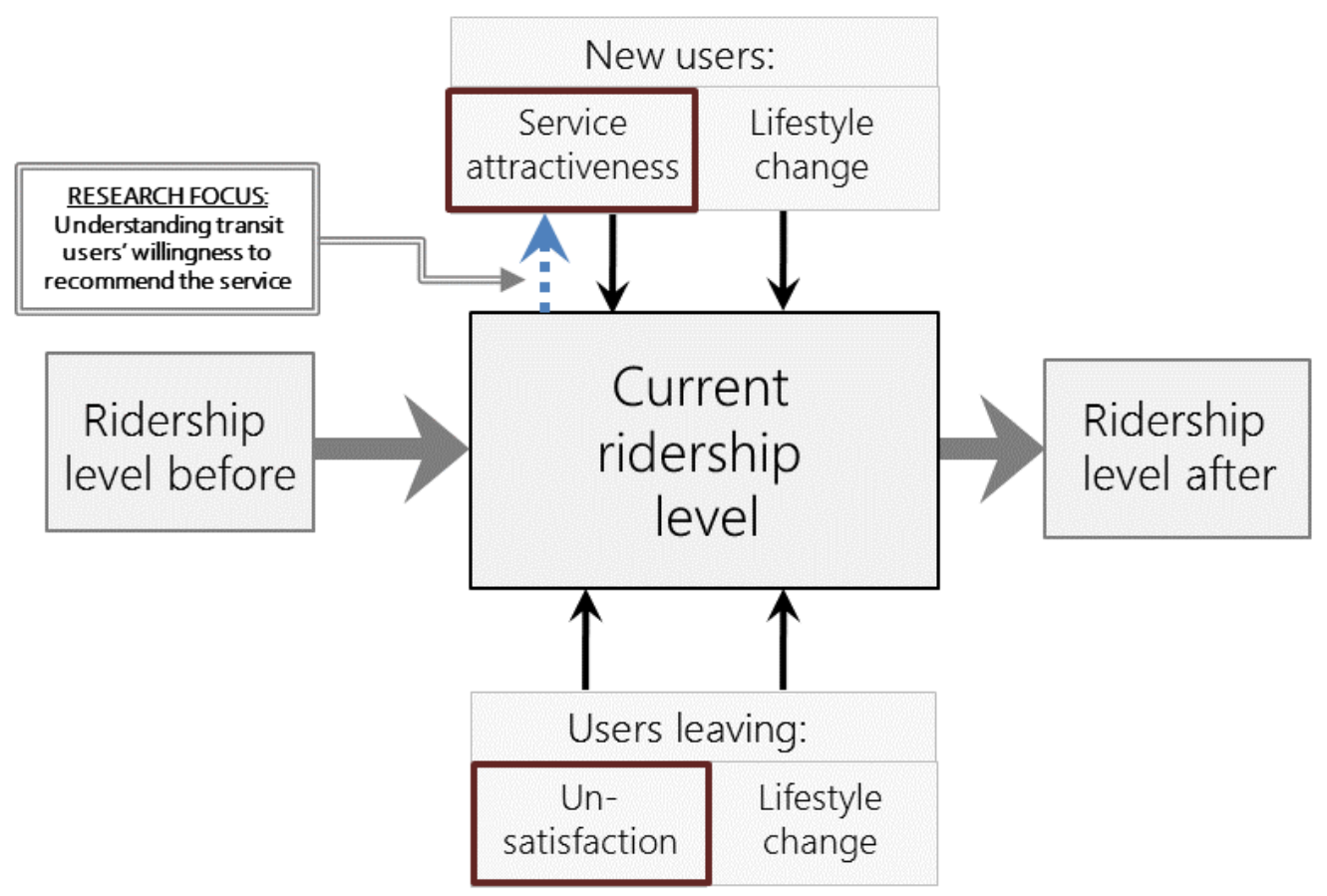

Figure 3: The determinants of ridership levels

\section{STUDY LIMITATIONS AND FUTURE RESEARCH}

The findings of this paper are an important stepping-stone in determining users' willingness to recommend the service to others and the relationship with passengers' intentions to continue using the service. However, some study limitations exist. The first is that this analysis does not attempt to model individual's likeliness to continue using transit. Rather, it investigates the relationship between willingness to recommend and intended continued use. In fact, with the 
available data, which was a result of a short field survey with a limited number of questions, it was not possible to fully investigate the impact of users' likeliness to continue using transit in the future. Thus, we recommend that future studies carefully conduct in-depth interviews to investigate users' intentions to continue using transit, while accounting for other important variables that may have an effect, such as, income, and changes in work/study status.

While the data for this research concerning willingness to recommend was collected as a binary variable, future studies could analyze willingness to recommend the service based on different scales through in-depth interviews to better understand the appropriateness of a variety of methods or question structures. A similar study is even more important in understanding the complex nature of users' intentions to continue using the service in the future. Nevertheless, in this research, we used data that is derived from a survey question that accepted a variety of response-types in order to gain the best possible understanding of users' intentions.

Finally, although at-stop surveys offer a good opportunity to observe the users' actual behavior (e.g., actual waiting time) to augment the surveys responses (Diab \& El-Geneidy, 2014; Hess et al., 2004; Mishalani et al., 2006; Psarros et al., 2011), they have a limitation of the inconsistency in participants being able to complete the questionnaire and missing the later arrivals (who arrive immediately before the bus arrivals). Consequently, the variables of home postal code and gender were missing for many respondents and could not be used in this analysis. Therefore, using modern data collection techniques such as automatic vehicle location (AVL) data as well as cellular data and smart phone apps (with the consent of respondents) to track users' actual waiting time could help to accomplish a similar study without missing any of the variables or riders. However, despite these limitations, this study enriches the literature by providing a deeper understanding of the factors that increase users' likelihood to recommend the 
service to others. Indeed, it is important for transit agencies to find ways for their existing

passengers to promote the service to others and thereby help to increase ridership.

\section{REFERENCES}

Ajzen, I. (1985). From intentions to actions: A theory of planned behavior. In J. K. J.Beckmann (Ed.), Action-control: From cognition to behavior. Heidelberg, Germany Springer.

Barlow, S., \& Clark, H. (2006). Findings of customer surveys conducted for Sacramento Regional Transit. Retrieved from Sacramento, USA: http:/www.sacrt.com/documents/Custsatisfactionfinal.pdf

Carreira, R., Patrício, L., Natal, J., \& Magee, C. (2014). Understanding the travel experience and its impact on attitudes, emotions and loyalty towards the transportation provider-A quantitative study with mid-distance bus trips. Transport Policy, 31, 35-46.

Chen, C. (2008). Investigating structural relationships between service quality, perceived value, satisfaction, and behavioral intentions for air passengers: Evidence from Taiwan.

Transportation Research Part A: Policy and Practice, 42(4), 709-717.

Chen, C., \& Chao, W. (2011). Habitual or reasoned? Using the theory of planned behavior, technology acceptance model, and habit to examine switching intentions toward public transit. Transportation Research Part F: Traffic Psychology and Behaviour, 14(2), 128137. doi:http://dx.doi.org/10.1016/j.trf.2010.11.006

Conlon, M., Foote, P., O'Malley, K., \& Stuart, D. (2001). Successful arterial street limited-stop express bus service in Chicago. Transportation Research Record: Journal of the Transportation Research Board(1760), 74-80. doi:doi:10.3141/1760-10

de Oña, J., de Oña, R., Eboli, L., Forciniti, C., \& Mazzulla, G. (2016). Transit passengers’ behavioural intentions: The influence of service quality and customer satisfaction. Transportmetrica A: Transport Science, 12(5), 385-412.

de Oña, J., de Oña, R., Eboli, L., \& Mazzulla, G. (2016). Index numbers for monitoring transit service quality. Transportation Research Part A: Policy and Practice, 84(0), 18-30. doi:http://dx.doi.org/10.1016/j.tra.2015.05.018

dell'Olio, L., Ibeas, A., \& Cecín, P. (2011). The quality of service desired by public transport users. Transport Policy, 18(1), 217-227.

Diab, E., Badami, M., \& El-Geneidy, A. (2015). Bus transit service reliability and improvement strategies: Integrating the perspectives of passengers and transit agencies in North America. Transport Reviews, 35(3), 292-328.

Diab, E., \& El-Geneidy, A. (2014). Transitory optimism: Changes in passenger perception following bus service improvement over time. Transportation Research Record: Journal of the Transportation Research Board(2415), 97-106. doi:doi:10.3141/2415-11

Evans, J. (2004). Transit scheduling and frequency: In traveler response to transportation system changes. Retrieved from Washington D.C:

Friman, M., \& Fellesson, M. (2009). Service supply and customer satisfaction in public transportation: The quality paradox. Journal of Public Transportation, 12(4), 57-69. 
Grimsrud, M., \& El-Geneidy, A. (2013). Driving transit retention to renaissance: Trends in Montreal commute public transport mode share and factors by age group and birth cohort. Public transport: Planning and Operations, 5(3), 119-241.

Grimsrud, M., \& El-Geneidy, A. (2014). Transit to eternal youth: Lifecycle and generational trends in Greater Montreal public transport mode share. Transportation, 41(1), 1-19.

Hayes, B. (1997). Measuring customer satisfaction: survey design, use, and statistical analysis methods (2 ed.). Milwaukee, Wisconsin: ASQ Quality Press.

Heath, Y., \& Gifford, R. (2002). Extending the theory of planned behavior: predicting the use of public transportation1. Journal of Applied Social Psychology, 32(10), 2154-2189.

Hess, D., Brown, J., \& Shoup, D. (2004). Waiting for the Bus. Journal of Public Transportation, 7(4), 67-84.

Idris, A., Habib, K., \& Shalaby, A. (2014). Dissecting the role of transit service attributes in attracting commuters: Lessons from a comprehensive revealed preference-stated preference study on commuting mode-switching behavior in Toronto, Ontario, Canada. Transportation Research Record: Journal of the Transportation Research Board(2415), 107-117.

Imaz, A., Nurul Habib, K., Shalaby, A., \& Idris, A. (2015). Investigating the factors affecting transit user loyalty. Public Transport, 7(1), 39-60. doi:10.1007/s12469-014-0088-x

Lai, W., \& Chen, C. (2011). Behavioral intentions of public transit passengers-The roles of service quality, perceived value, satisfaction and involvement. Transport Policy, 18(2), 318-325. doi:http://dx.doi.org/10.1016/j.tranpol.2010.09.003

Levinson, D., \& Krizek, K. (2008). Planning for place and plexus: Metropolitan land use and transport. New York: Routledge.

Mishalani, R., McCord, M., \& Wirtz, J. (2006). Passenger wait time perceptions at bus stops: Empirical results and impact on evaluating real-time bus arrival information. Journal of Public Transportation, 9(2), 89-106.

Molander, S., Fellesson, M., Friman, M., \& Skålén, P. (2012). Market orientation in public transport $\mathrm{r}$ esearch - A review. Transport Reviews, 32(2), 155-180.

Murphy, K. (2014). Société de transport de Montréal (STM) aims to boost ridership by $40 \%$ with a mobile app. Retrieved from http://sapinsider.wispubs.com/Assets/CaseStudies/2014/January/STM

Perk, V., Flynn, J., \& Volinski, J. (2008). Transit ridership, reliability and retention. Retrieved from Florida:

Psarros, I., Kepaptsoglou, k., \& Karlaftis, m. (2011). An Empirical investigation of passenger wait time perceptions using hazard-based duration models. Journal of Public Transportation, 14(3), 109-122.

Reichheld, F. (2003). The one number you need to grow. Harvard business review, 81(12), 4655.

Sadhukhan, S., Banerjee, U., \& Maitra, B. (2014). Commuters' perception towards transfer facility attributes in and around metro stations: Experience in kolkata. Journal of Urban Planning and Development.

Simma, A., \& Axhausen, K. (2003). Commitments and modal usage: Analysis of German and Dutch panels. Transportation Research Record: Journal of the Transportation Research Board(1854), 22-31.

Spears, S., Houston, D., \& Boarnet, M. (2013). Illuminating the unseen in transit use: A framework for examining the effect of attitudes and perceptions on travel behavior. 
Transportation Research Part A: Policy and Practice, 58, 40-53.

doi:http://dx.doi.org/10.1016/j.tra.2013.10.011

Susilo, O., \& Cats, O. (2014). Exploring key determinants of travel satisfaction for multi-modal trips by different traveler groups. Transportation Research Part A: Policy and Practice, 67, 366-380. doi:http://dx.doi.org/10.1016/j.tra.2014.08.002

Transportation Research Board. (1999). A handbook for measuring customer satisfaction and service quality -TCRP Report 47. Retrieved from Washington, DC:

Transportation Research Board. (2003). Transit Information and Promotion-Traveler Response to Transportation System Changes -TCRP Report 95. Retrieved from Washington, DC:

Tyrinopoulos, Y., \& Antoniou, C. (2008). Public transit user satisfaction: Variability and policy implications. Transport Policy, 15(4), 260-272.

van Lierop, D., \& El-Geneidy, A. (2015). Getting committed: A perspective on public transit market segmentation. Paper presented at the the 94th Annual Meeting of the Transportation Research Board, Washington, D.C., USA.

Watkins, K., Ferris, B., Borning, A., Rutherford, G., \& Layton, D. (2011). Where is my bus? Impact of mobile real-time information on the perceived and actual wait time of transit riders. Transportation Research Part A: Policy and Practice, 45(8), 839-848.

doi:http://dx.doi.org/10.1016/j.tra.2011.06.010 